\title{
Studi Korelasi antara Kapasitas Daya Motor Electrical Submersible Pump terhadap 4 Parameter Sumur Minyak
}

\author{
DECY NATALIANA, NANDANG TARYANA, RIDWAN ARIF AKBAR
}

\author{
Teknik Elektro Institut Teknologi Nasional Bandung \\ Email: decy@itenas.ac.id
}

Received 27 Agustus 2017 | Revised 22 Desember 2017 | Accepted 23 Desember 2017

\begin{abstract}
ABSTRAK
Electrical Submersible Pump (ESP) merupakan salah satu sistem pumping yang digunakan dalam produksi minyak bumi dengan menggunakan motor induksi sebagai penggerak utama yang ditanamkan ke dalam sumur. Seperti yang telah diketahui bahwa kinerja sistem ESP yang digunakan di PT Baker Hughes Indonesia, berlangsung secara terus-menerus. Hal ini dapat mempengaruhi kinerja motor yang menyebabkan hasil produksi menurun. Hasil produksi minyak mentah berbeda-beda untuk masing-masing wellpad, dimana 1 wellpad terdiri dari beberapa sumur dan masing-masing sumur memiliki kedalaman yang berbeda sehingga kapasitas motor dan pompa yang digunakan berbeda pula. Kapasitas pompa sangat bergantung pada parameter sumur minyak yaitu kedalaman sumur, Total Dynamic Head (TDH), hasil produksi perjam, dan hasil produksi perhari per-TDH. Oleh karena itu, dapat ditentukan korelasi antara kapasitas Motor ESP terhadap keempat paramter sumur tersebut. Berdasarkan hasil pengolahan data dan analisis sistem diperoleh bahwa kapasitas daya motor berbanding lurus secara linier terhadap keempat parameter tersebut.
\end{abstract}

Kata Kunci: ESP, wellpad, hasil produksi, kapasitas daya motor.

\section{ABSTRACT}

Electrical Submersible Pump (ESP) is one of the pumping system used in the production of petroleum by using an induction motor as the prime mover which are implanted into the well. As we known that the performance of the ESP system which is used in PT Baker Hughes Indonesia, has worked continuously. This can affect motor performance which led to decreased production yield. The production of crude oil varies for each well pad, that 1 well pad consists of several wells and each well has a different depth so that the capacity of the motor and pump are used differently. Pump capacity is very dependent on the parameters of the oil wells, the depth of the well, Total Dynamic Head (TDH), the hourly production and production per day per-TDH. Therefore, we can determine the correlation between the motor power againts the four well's parameters. Based on the results of data processing and systems analysis showed that the motor power linearly proportional to the four parameters.

Keywords: ESP, well pad, production, capacity motor power. 


\section{PENDAHULUAN}

Setelah memasuki tahun 2007, teknologi di dunia perminyakan mulai berkembang di Indonesia khususnya di Provinsi Riau yang ditandai dengan adanya Sistem Electrical Submersible Pump (ESP) sebagai pengganti Rod Pump di tiap-tiap sumur minyak. Electrical Submersible Pump merupakan suatu alat berupa pompa yang memiliki penggerak utamanya adalah motor induksi yang terintegrasi dan terpasang pada pompa dan sensornya. ESP ini ditanamkan di dalam sumur minyak yang bekerja dengan gaya sentrifugal untuk mengangkut minyak bumi di dalam sumur ke atas permukaan.

Kinerja sistem ESP berlangsung 24/7 atau yang dikenal dengan 24 jam / 7 hari non-stop. Secara tidak langsung, produksi minyak mentah akan berlangsung tanpa henti hingga minyak mentah pada sumur minyak menipis dan tak dapat berproduksi kembali (Baker Hughes Indonesia, 2009).

Hasil produksi minyak mentah untuk masing-masing wellpad berbeda-beda karena tiap wellpad terdiri dari lebih dari 2 sumur minyak dengan kedalaman yang berbeda-beda sehingga sistem ESP yang dipasang akan memiliki spesifikasi sistem yang berbeda pula, baik dari segi pompa, motor, dan juga sensor(Havard Devold,2013).

Wellpad merupakan sebuah landasan atau area yang digunakan sebagai tempat untuk berdirinya pumping unit. Pumping unit yang digunakan adalah sistem ESP, yang terdapat beberapa jenis dan tipe berdasarkan lokasi wellpad berada (Robi Irsamukhti, PLTP Kamojang, 2012). Jenis dan tipe akan mempengaruhi jumlah hasil produksinya sehingga dapat dilihat karakteristik dari ESP yang digunakan terhadap faktor-faktor yang mempengaruhi kinerja dari sistem tersebut.

Pada studi ini dipelajari korelasi antara sistem ESP khususnya karakteristik Motor ESP terhadap parameter yang mempengauhi karaktersitik motor berupa kedalaman sumur, Total Dynamic Head, dan juga hasil produksinya.

Tujuan dalam studi kasus ini adalah untuk mempelajari studi korelasi antara kapasitas daya output motor ESP terhadap parameter kedalaman sumur (Depth), Total Dynamic Head $(T D H)$, hasil produksi fluida perjam $(\mathrm{BFPH})$, dan juga hasil produksi tiap hari per-TDH (BFPD/TDH).

\section{METODOLOGI PENELITIAN}

\subsection{Deskripsi Kerja Sistem}

Di dalam metoda penelitian, dijelaskan tentang blok diagram sistem dan deskripsi cara kerja sistem. Dalam hal ini akan dijelaskan cara kerja sistem yang berkaitan dengan studi korelasi daya output motor terhadap parameter-parameter sumur dengan menggunakan pumping unit yaitu berupa sistem ESP milik PT Baker Hughes Indonesia.

Gambar 1 menggambarkan cara kerja sistem ESP. Sistem kerja ini terdiri dari input, controller, aktuator, motor, dan output. 


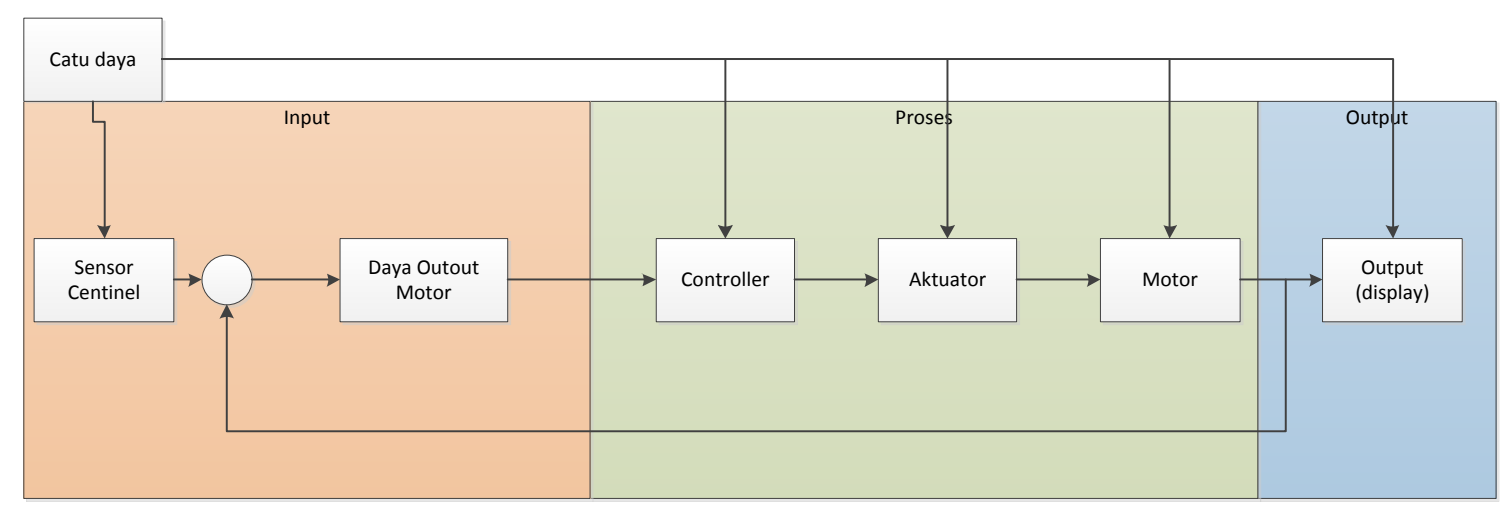

Gambar 1. Blok diagram sistem ESP

Berikut penjelasan tentang masing-masing bagian dari blog diagram tersebut:

a. Input

Pada bagian input, sistem ini menggunakan sensor Centinel. Sensor ini dapat mengukur kondisi kerja motor. Agar dapat menentukan korelasi antara motor terhadap 4 parameter sumur, sensor Centinel akan mengukur arus dan tegangan output dari motor sehingga diperoleh nilai daya output motor. Gambar 2 adalah sensor Centine/yang digunakan.

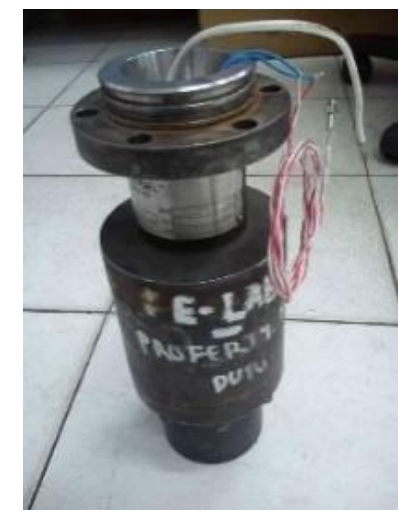

Gambar 2. Sensor Centinel

b. Controller

Controller yang digunakan dalam sistem ini adalah GCS Vortex Motor Controller. Controller ini dapat memantau dan mengendalikan kondisi motor di dalam sumur minyak. Controller yang digunakan terlihat pada Gambar 3.

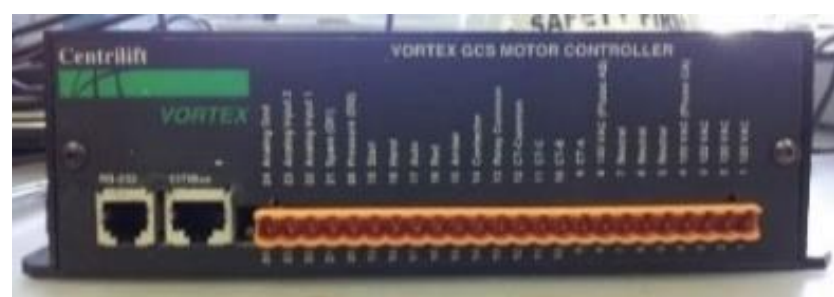

Gambar 3. GCS Vortex Motor Controller 
c. Aktuator

Pada bagian aktuator, controller dihubungkan pada sebuah panel Variable Speed Drive (VSD) yang di dalamnya terdiri dari fuse (sikring), kontaktor, dan relay-relay yang berfungsi mengubah sinyal digital dari sensor menjadi sinyal analog dan juga sebaliknya. Aktuator yang digunakan terlihat pada Gambar 4.

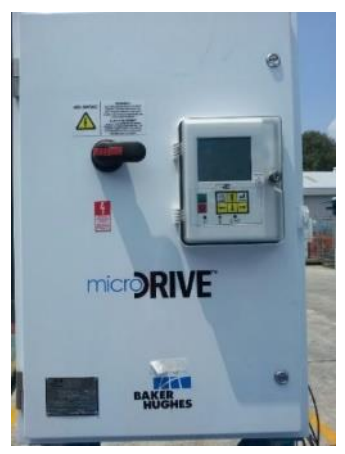

\section{Gambar 4. Variable Speed Drive (VSD)}

d. Plant Sistem

Plant pada sistem ini adalah pompa yang terintegrasi dengan motor. Motor yang digunakan merupakan motor induksi yang bekerja sebagai penggerak pompa dengan menggunakan gaya sentrifugal untuk mengangkut minyak mentah dari dalam sumur minyak. Motor induksi yang digunakan dapat dilihat pada Gambar 5.

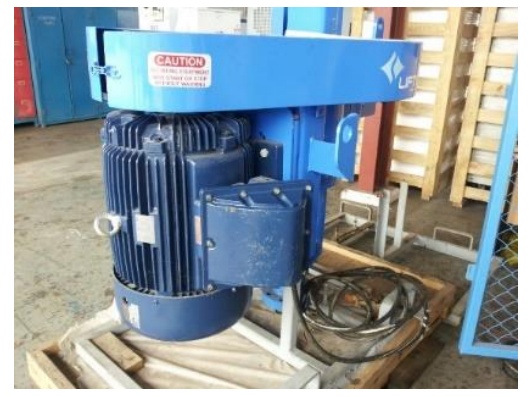

\section{Gambar 5. Motor induksi}

e. Output Sistem

Output sistem ini merupakan bagian display dari GCS Cortex Motor Controller yang berfungsi sebagai Human Machine Interface (HMI) yang ditempel pada panel VSD. Output display yang dapat dilihat pada Gambar 6.

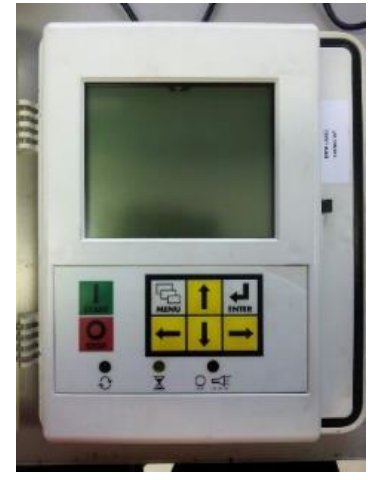

Gambar 6. GCS Vortex Display 


\subsection{Konstruksi Sistem ESP}

Konstruksi untuk tiap wellpad dan sumur minyak memiliki konstruksi pumping system yang sama yaitu menggunakan sistem ESP yang dapat dilihat pada Gambar 7. Pokok penting yang menjadi pembahasan dari studi korelasi daya output motor terhadap 4 parameter sumur, yaitu kedalaman sumur, Total Dynamic Head, pompa ESP dan juga motor ESP.

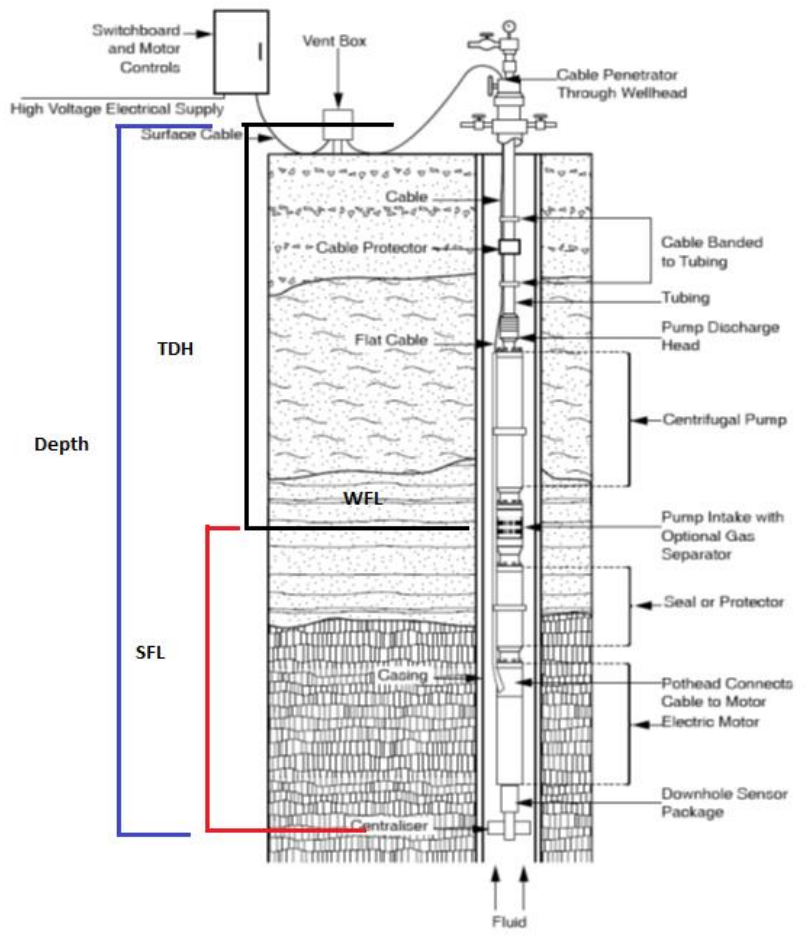

Gambar 7. Konstruksi ESP

\subsubsection{Kedalaman Sumur (Depth)}

Kedalaman sumur dapat mempengaruhi jumlah stage dan daya motor yang akan digunakan dalam produksi minyak. Dalam kasus ini, sumur yang akan ditinjau memiliki kedalaman yang berbeda.

Dari 5 sumur tersebut, dapat dilihat kedalamannya masing-masing pada Tabel 1.

Tabel 1. Tabel Kedalaman Sumur

\begin{tabular}{|r|l|r|l|}
\hline No & \multicolumn{1}{|c|}{ Nama Sumur } & Depth (ft) & Keterangan \\
\hline 1 & Sumur A & 1141 & Wellpad ABC \\
\hline 2 & Sumur B & 1134 & Wellpad ABC \\
\hline 3 & Sumur C & 1114 & Wellpad ABC \\
\hline 4 & Sumur B0235 & 2219 & Wellpad Bangko \\
\hline 5 & Sumur BK180 & 3638 & Wellpad Bekasap \\
\hline
\end{tabular}

\subsubsection{Total Dynamic Head (TDH)}

Total Dynamic Head (TDH) merupakan total jarak dari wellhead hingga pump intake, yang terdiri dari jarak beberapa bagian yaitu wellhead ke head, head ke tubing, dan tubing ke pump intake. Pd merupakan singkatan dari Pad atau dikenal dengan sebutan wellhead. Hd 
merupakan singkatan dari Head atau bagian atas pipa di dalam sumur. Sedangkan Ft merupakan Foot atau bagian bawah pipa di dalam sumur, seperti yang dapat dilihat pada Gambar 8.

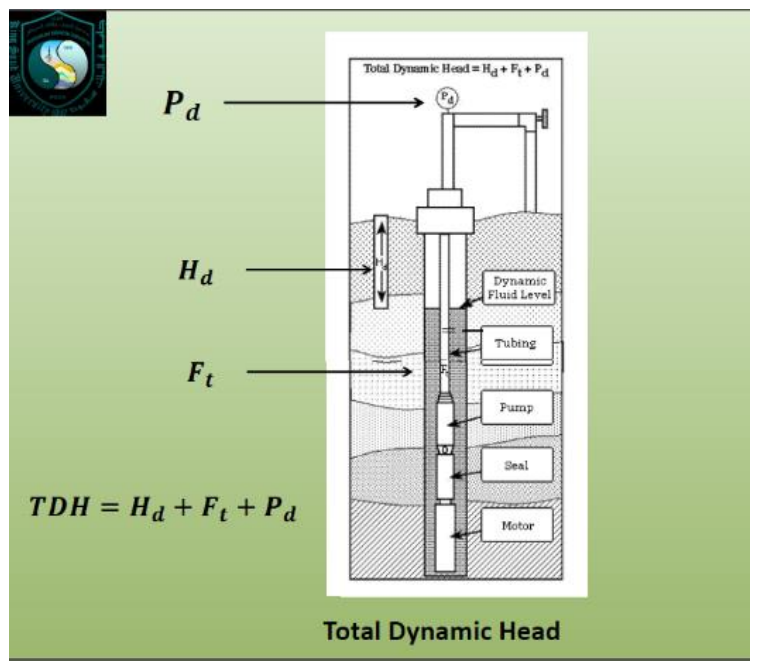

Gambar 8. Total Dynamic Head

Total Dynamic Head (TDH) sangat bergantung pada jarak kedalaman sumur. Semakin dalam sumur tersebut, maka semakin besar pula jarak TDH-nya. Besarnya jarak TDH tersebut dapat mencapai 1/2 hingga 2/3 dari jarak kedalaman sumur, karena bergantung pada daerah kerja fluida atau Work Fluid Level (WFL) yang akan mempengaruhi hasil produksi.

Selain itu, di dalam sumur minyak juga terdapat daerah fluida yang tidak dapat diangkut oleh pompa ESP yang disebut Static Fluid Level (SFL). Dari penelitian ini, 5 sumur tersebut memiliki daerah jarak TDH, daerah WFL dan SFL yang berbeda yang dapat dilihat pada Tabel 2.

Tabel 2. Tabel TDH, WFL, dan SFL pada Sumur

\begin{tabular}{|l|l|r|r|r|r|}
\hline No & Nama Sumur & Depth (ft) & TDH (ft) & WFL (ft) & SFL (ft) \\
\hline 1 & Sumur A & 1141 & 625 & 625 & 516 \\
\hline 2 & Sumur B & 1134 & 626 & 626 & 508 \\
\hline 3 & Sumur C & 1114 & 606 & 606 & 508 \\
\hline 4 & Sumur B0235 & 2219 & 1737 & 1737 & 482 \\
\hline 5 & Sumur BK180 & 3638 & 2166 & 2166 & 1472 \\
\hline
\end{tabular}

Titik kerja pada pump intake adalah Work Fluid Level, sedangkan jarak di bawah titik pump intake yang terdapat fluida statik adalah Static Fluid Level (SFL) yang dapat mempengaruhi banyaknya jumlah stage yang dibutuhkan pada pompa.

\subsubsection{Pompa ESP}

Pompa ESP merupakan peralatan utama dalam proses produksi minyak. Hasil produksi bergantung pada jumlah stage yang dimiliki oleh pompa tersebut. 
Pompa yang digunakan sebanyak 5 jenis pompa yang terpasang di masing-masing sumur tersebut. Berikut tabel spesifikasi dari masing-masing pompa yang digunakan pada Tabel 3.

Tabel 3. Tabel Spesifikasi Pompa

\begin{tabular}{|c|c|c|c|c|c|c|}
\hline No & $\begin{array}{l}\text { Jenis } \\
\text { Pompa }\end{array}$ & $\begin{array}{l}\text { Jumlah } \\
\text { Stage }\end{array}$ & Daya Input & $\begin{array}{l}\text { Efisiensi } \\
\text { Pompa }\end{array}$ & Fungsi & Keterangan \\
\hline 1 & DN1300 & 72 & 30HP & $59 \%$ & Intake / Seal & Sumur A \\
\hline 2 & P16 & 39 & 38HP & $60 \%$ & Intake / Seal & Sumur B \\
\hline 3 & P16 & 39 & 38HP & $60 \%$ & Intake / Seal & Sumur C \\
\hline 4 & P37 & 37 & 95HP & $60 \%$ & Intake / Seal & Sumur B0235 \\
\hline 5 & P10 & 113 & 63HP & $60 \%$ & Intake / Seal & Sumur BK180 \\
\hline
\end{tabular}

Daya input pompa bergantung pada daya output motor yang digunakan. Tetapi, efisiensi yang dimiliki pompa hanya berkisar $60 \%$ meskipun menggunakan stage yang banyak. Dalam studi korelasi ini, spesifikasi pompa digunakan sebagai variabel tetap yang dijadikan sebagai batasan masalah.

\subsubsection{Motor ESP}

Motor ESP merupakan motor induksi yang bekerja akibat aliran sumber tegangan pada stator sehingga menimbulkan fluks magnetik yang akan menginduksikan ke rotor. Induksi magnetik tersebut akan menimbulkan medan putar dan menghasilkan kecepatan sinkron. Kecepatan sinkron dapat dirumuskan pada Persamaan 1 sebagai berikut:

$$
\text { Ns }=120 \times \frac{f}{p}
$$

Dimana :

$$
\begin{array}{ll}
\text { Ns } & \text { : Kecepatan Sinkron (Rpm) } \\
\mathrm{f} & : \text { Frekuensi }(\mathrm{Hz}) \\
\mathrm{p} & : \text { Jumlah Kutub }
\end{array}
$$

Komponen utama motor ESP ini memiliki celah udara antara stator dan rotor seperti halnya dengan motor induksi yang dapat menimbulkan slip sekitar $100 \mathrm{Rpm}$. Oleh karena itu, kecepatan sinkron maksimum untuk frekuensi $60 \mathrm{~Hz}$ adalah $3500 \mathrm{Rpm}$ dapat dilihat pada Gambar 9.
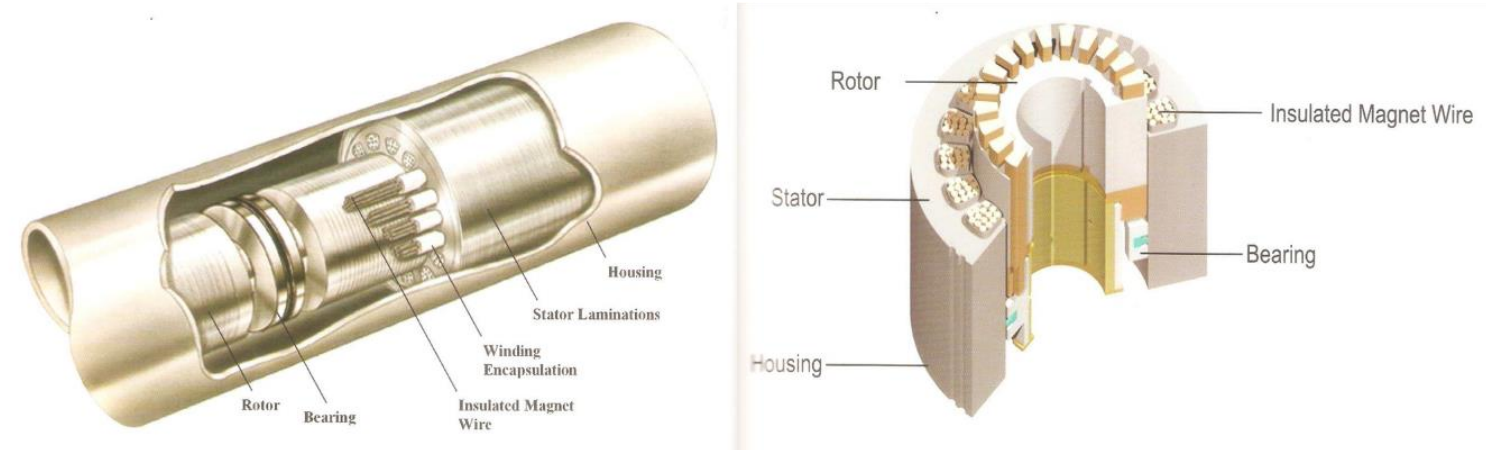

Gambar 9. Motor ESP 
Pada motor induksi, perputaran rotor akan menimbulkan gaya yang disebut Torka. Torka dapat dirumuskan dengan Persamaan 2 sebagai berikut:

$$
T=\frac{P o}{\omega}
$$

Dengan :

$$
\omega=\text { kecepatan sudut kecepatan sudut }
$$

Kecepatan sudut :

$$
\omega=\frac{2 \pi}{60} \times N r
$$

maka :

$$
T=\frac{P_{o}}{\left(\frac{2 \pi}{60}\right) \cdot N r}=\frac{60}{2 \pi} \times \frac{P_{o}}{N r}=9,55 \times \frac{P o}{N r}
$$

Dimana :

$$
\begin{array}{ll}
\mathrm{T} & : \text { Torka }(\mathrm{Nm}) \\
\mathrm{Po} & : \text { Daya Output }(\mathrm{Kw}) \\
\mathrm{Nr} & : \text { Kecepatan Rotor (Rpm) }
\end{array}
$$

Torka yang dihasilkan akan menggerakkan shaft pada pompa ESP. Jika torka melebihi batas maksimum dapat mengakibatkan kerusakan pada shaft sehingga ESP tidak berfungsi.

Efisiensi motor didapatkan dari perbandingan daya output dan daya input dalam persen (\%) sesuai dengan Persamaan 5 dan 6.

Efisiensi motor,

$$
\begin{array}{r}
P o=\frac{T \times N r}{9,55} \\
P i=\sqrt{3} \times V_{L L} \times I_{L} \times \cos \emptyset
\end{array}
$$

Biasanya efisiensi motor induksi berkisar antara 80\% hingga 90\%. Efisiensi tergantung juga dari beban yang ada. Karakterstik motor ESP untuk beberapa motor yang digambarkan dalam kurva nameplate ESP dapat dilihat pada Gambar 10. 


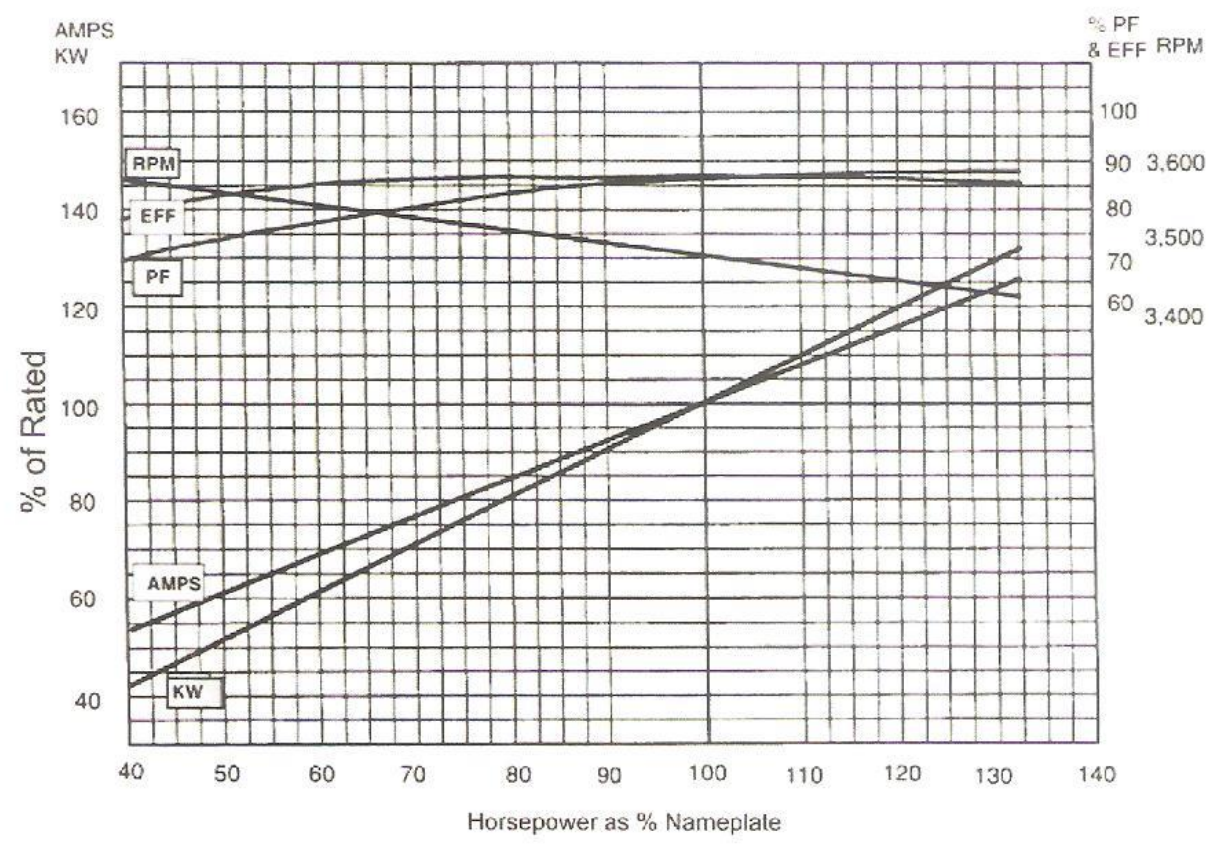

Gambar 10. Kurva Efisiensi Motor ESP Berdasarkan Nameplate

Di dalam penelitian studi korelasi motor terhadap parameter sumur ini, digunakan beberapa tipe motor induksi untuk kelima sumur yang memiliki kedalaman sumur yang berbeda. Spesifikasi motor ESP berdasarkan nameplate yang digunakan dalam studi korelasi daya output motor terhadap 4 parameter sumur dapat dilihat pada Tabel 4.

Tabel 4. Spesifikasi Motor ESP

\begin{tabular}{|c|c|c|c|c|c|c|}
\hline No & $\begin{array}{l}\text { Daya } \\
\text { Output }\end{array}$ & V input (V) & I input (A) & Kapasitas Motor & $\begin{array}{l}F \\
5 \emptyset)\end{array}$ & Keterangan \\
\hline 1 & 30HP & 435 & 45 & $3500 \mathrm{RPM}, 60 \mathrm{~Hz}$ & 0.65 & Sumur A \\
\hline 2 & 38HP & 435 & 53 & $3500 \mathrm{RPM}, 60 \mathrm{~Hz}$ & 0.65 & Sumur B \\
\hline 3 & 38HP & 435 & 53 & $3500 \mathrm{RPM}, 60 \mathrm{~Hz}$ & 0.65 & Sumur C \\
\hline 4 & 95HP & 840 & 69 & 3500 RPM, $60 \mathrm{~Hz}$ & 0.65 & Sumur B0235 \\
\hline 5 & 63HP & 980 & 39 & 3500 RPM, $60 \mathrm{~Hz}$ & 0.65 & Sumur BK180 \\
\hline
\end{tabular}

\subsection{Korelasi Daya Output Motor ESP terhadap 4 Parameter Sumur}

Data hasil monitoring yang diperoleh pada sistem ESP PT Baker Hughes Indonesia terhadap 5 sumur yang berbeda merupakan data real yang akan diolah dan dibandingkan terhadap hasil perhitungannya. Sehingga karakteristik motor ESP dapat diperoleh dari kurva korelasi daya output motor terhadap 4 parameter sumur. Pada konstruksi ESP, bagian Total Dynamic Head sebesar 1/2 hingga 2/3 kedalaman sumur merupakan jarak TDH, dan sisanya adalah jarak SFL. Jadi, kedalaman sumur dapat diartikan sebagai jumlah jarak SFL dan TDH sehingga dapat dituliskan dalam Persamaan 7.

$$
\text { Depth }=S F L+T D H
$$


Selain itu, TDH dapat dihitung menggunakan Persamaan 8, berdasarkan sumber: Baker Hughes Centrilift Submersible Pump Handbook.

$$
T D H=\frac{B H P \times C \times \text { Pout }}{P \operatorname{in} \times B F P D}
$$

Dengan adanya keterbatasan daya output pada motor, maka dapat ditentukan kedalaman ideal pada suatu sumur dengan menggunakan Persamaan 9.

$$
\text { Depth }=S F L+\frac{B H P \times C \times P \text { out }}{P \text { in } \times B F P D}
$$

Keterangan:

$$
\begin{array}{ll}
\text { Depth } & \text { : Kedalaman Sumur }(\mathrm{ft}) \\
\text { SFL } & \text { : Static Fluid Level }(\mathrm{ft}) \\
\text { BHP } & \text { : Brake Horse Power }(\mathrm{KW}) \\
\mathrm{C} & : \text { Constant }(3960) \\
\text { P out } & \text { : Daya Output Motor }(\mathrm{KW}) \\
\text { P in } & \text { : Daya Input Motor }(\mathrm{KW}) \\
\text { BFPD } & \text { : Barel Fluid Perday }(\mathrm{Bpd})
\end{array}
$$

Debit maksimum atau hasil produksi fluida yang optimal memiliki satuan GPM atau Galoon Per Minute sehingga dibutuhkan konversi nilai GPM ke BFPD untuk mengubah nilai satuannya. Berdasarkan sumber: Baker Hughes Centrilift Submersible Pump Handbook, persamaan untuk mengubah GPM ke BFPD dapat dilihat pada Persamaan 10.

$$
B F P D i=G P M \times 34.3
$$

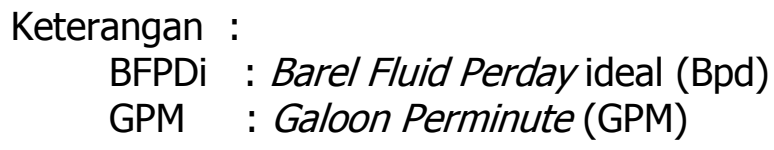

Dari sumber yang sama, korelasi daya output motor terhadap hasil produksi dapat ditentukan berdasarkan Persamaan 11:

$$
P \text { out }=\frac{G P M \times T D H \times S p \cdot G r}{C}
$$

Sehingga dapat diperoleh persamaan hasil produksi idealnya pada Persamaan 12.

$$
B F P D i=\frac{P \text { out } \times C \times 34.3}{T D H \times S p . G r .}
$$

Dengan memperoleh persamaan korelasi antara daya output motor terhadap hasil produksi ideal perhari (12), maka dapat diperoleh persamaan hasil produksi ideal perjamnya seperti pada Persamaan 13.

$$
B F P H i=\frac{P \text { out } \times C \times 34.3}{24 \times T D H \times S p . G r} .
$$

Keterangan:

BFPHi : Barel Fluid Perhour ideal (Bph)

Sp.Gr. : Spec Gravity (1.00) 
Berdasarkan Persamaan 13, dapat diturunkan persamaan korelasi daya output motor terhadap parameter sumur yang terakhir yaitu BFPDi/TDHi pada Persamaan 14.

$$
\frac{B F P D i}{T D H i}=\frac{P \text { out } \times C \times 34.3}{T D H^{2} \times S p \cdot G r}
$$

\subsection{Friction Loss}

Fluida yang mengalir di dalam pipa maka akan mengalami tegangan geser (shear stress) pada dinding pipa, sehingga terjadi kehilangan sebagian tenaga yang sering disebut dengan friction loss. Persamaan gradien tekanan pada umumnya digunakan untuk setiap fluida yang mengalir pada sudut kemiringan pipa tertentu yang dinyatakan dengan tiga komponen, yaitu :

a. Adanya perubahan energi potensial (elevasi).

b. Adanya gesekan pada dinding pipa.

c. Adanya perubahan energi kinetik.

Darcy dan Weisbah's menghitung kehilangan energi karena gesekan dengan persamaan :

$$
\mathrm{h}=\mathrm{f} \frac{L v^{2}}{d \cdot 2 g}
$$

Keterangan :

$$
\begin{aligned}
& \mathrm{h}=\text { friction loss, } \mathrm{ft} \\
& \mathrm{f}=\text { friction factor } \\
& \mathrm{L}=\text { Panjang pipa, } \mathrm{ft} \\
& \mathrm{V}=\text { kecepatan aliran rata-rata dalam pipa, } \mathrm{ft} / \mathrm{s}^{2}
\end{aligned}
$$

Berdasarkan persamaan 15, Wiliam-hazen membuat suatu persamaan empiris untuk friction loss (hf), yaitu :

$$
\mathrm{hf}=2,0830\left[\frac{100}{C}\right]^{1,85}\left[\frac{(Q / 34.3)^{1,85}}{I D^{4.8655}}\right]
$$

Dimana :

$\mathrm{hf}=$ feet friction loss per 1000 feet

$\mathrm{C}=120=$ Konstanta dari bahan yang digunakan dalam pembuatan pipa

$\mathrm{Q}=\mathrm{BFPD}=$ laju produksi, bpd

ID $=3,375^{\prime \prime}$ (inch) $=$ diameter dalam pipa (sumber PT Baker Hughes Indonesia)

\section{HASIL PENGOLAHAN DATA DAN ANALISIS SISTEM}

Setelah dilakukan pengumpulan dari hasil monitoring sistem ESP di lapangan pada 5 sumur dengan kedalaman yang berbeda dan dilakukan pengolahan data, maka diperoleh data-data real yang menunjang untuk memperoleh korelasi daya ouput motor terhadap 4 parameter sumur yang dapat dilihat pada Tabel 5 . 
Tabel 5. Hasil Pengolahan Data Real

\begin{tabular}{|c|c|c|c|c|c|c|c|c|c|c|c|c|c|c|}
\hline No & Date & Wellpad & $\begin{array}{l}\text { Nama } \\
\text { Sumur }\end{array}$ & $\begin{array}{l}\text { Daya } \\
\text { Output } \\
\text { Motor } \\
\text { (KW) }\end{array}$ & $\begin{array}{l}\text { Daya } \\
\text { Input } \\
\text { Motor } \\
(\mathbf{K W})\end{array}$ & $\begin{array}{l}\text { BFPD } \\
\text { (Bpd) }\end{array}$ & $\begin{array}{l}\text { BFPH } \\
\text { (Bph) }\end{array}$ & $\underset{\text { (Bpd.ft) }}{\text { HHP }}$ & $\begin{array}{c}\text { BHP } \\
\text { (Bpd.ft) }\end{array}$ & $\begin{array}{l}\text { Depth } \\
\text { (ft) }\end{array}$ & $\begin{array}{c}\text { TDH } \\
\text { (ft) }\end{array}$ & $\begin{array}{l}\text { SFL } \\
\text { (ft) }\end{array}$ & $\begin{array}{l}\text { Thurst } \\
\text { /Stage } \\
\text { (ft/stg) }\end{array}$ & $\begin{array}{c}\text { BFPD } \\
\text { /TDH } \\
\text { (Bpd/ft) }\end{array}$ \\
\hline 1 & $\begin{array}{l}09- \\
\text { Jan- } \\
15\end{array}$ & Well $A B C$ & $\begin{array}{l}\text { Sumur } \\
\text { A }\end{array}$ & 22.37 & 29.54 & 1481.47 & 61.73 & 233.82 & 389.7 & 1141 & 625 & 516 & 7.13 & 2.37 \\
\hline 2 & $\begin{array}{l}19- \\
\text { Jun- } \\
15\end{array}$ & Well $A B C$ & $\begin{array}{l}\text { Sumur } \\
\text { B }\end{array}$ & 28.34 & 34.79 & 1703.23 & 70.97 & 269.25 & 448.75 & 1134 & 626 & 508 & 13.03 & 2.72 \\
\hline 3 & $\begin{array}{l}\text { 09- } \\
\text { Mar- } \\
15\end{array}$ & Well $A B C$ & $\begin{array}{l}\text { Sumur } \\
\text { C }\end{array}$ & 28.34 & 34.79 & 1557 & 64.87 & 238.27 & 397.11 & 1114 & 606 & 508 & 13.03 & 2.57 \\
\hline 4 & $\begin{array}{l}11- \\
\text { Jun- } \\
15\end{array}$ & $\begin{array}{l}\text { Well } \\
\text { Bekasap }\end{array}$ & $\begin{array}{l}\text { Sumur } \\
\text { BK180 }\end{array}$ & 46.98 & 57.68 & 1276.33 & 53.18 & 698.11 & 1163.53 & 3638 & 2166 & 1472 & 13.03 & 0.59 \\
\hline 5 & $\begin{array}{l}25- \\
\text { Jun- } \\
15\end{array}$ & $\begin{array}{l}\text { Well } \\
\text { Bangko }\end{array}$ & $\begin{array}{l}\text { Sumur } \\
\text { BO235 }\end{array}$ & 70.84 & 87.47 & 4544.33 & 189.35 & 1993.31 & 3322.18 & 2219 & 1737 & 482 & 13.03 & 2.62 \\
\hline
\end{tabular}

\subsection{Korelasi Daya Output Motor ESP terhadap Total Dynamic Head(TDH)}

Dari data Tabel 5, TDH pada Sumur A adalah sebesar $625 \mathrm{ft}(190,5 \mathrm{~m})$, Sumur B 626ft, Sumur C $606 \mathrm{ft}$ dan seterusnya, dibandingkan dengan data hasil perhitungan dengan Persamaan 8, maka diperoleh hasil data real dan perhitungan yang ditampilkan pada Tabel 6. Perhitungan dilakukan terhadap semua sumur. Data real dan hasil perhitungannya dimasukkan pada Tabel 6 dan diplot ke dalam grafik seperti pada Gambar 11.

Tabel 6. Hasil Pengolahan Data TDH Ideal

\begin{tabular}{|r|l|r|r|r|}
\hline No & Nama Sumur & Daya Output Motor (KW) & TDH (ft) & TDHi (ft) \\
\hline 1 & Sumur A & 22.37 & 625 & 788.87 \\
\hline 2 & Sumur B & 28.34 & 626 & 849.81 \\
\hline 3 & Sumur C & 28.34 & 606 & 822.64 \\
\hline 4 & Sumur BK180 & 46.98 & 2166 & 2940.28 \\
\hline 5 & Sumur BO235 & 70.84 & 1737 & 2344.65 \\
\hline
\end{tabular}

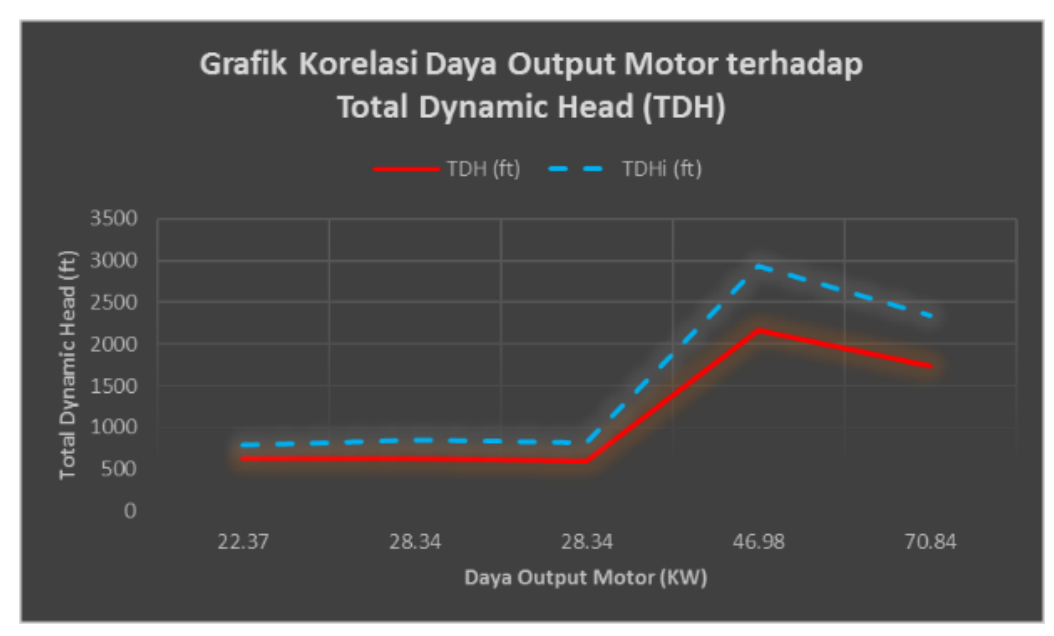

Gambar 11. Grafik Korelasi Daya Output Motor terhadap TDH 
Dari Tabel 6 dan Gambar 11, nilai TDH real pada sumur A, B dan C mendekati nilai TDH ideal, sedangkan Sumur BK180 dan Sumur BO235 masih jauh dari nilai idealnya. Hal ini menjelaskan bahwa untuk daya output motor sekitar $22 \mathrm{KW}$ hingga $30 \mathrm{KW}$ memiliki jarak TDH sekitar $800 \mathrm{ft}$.

Sedangkan untuk motor yang lebih besar dari $40 \mathrm{KW}$ memiliki jarak TDH lebih besar dari $1500 \mathrm{ft}$. Semakin besar daya output motor belum tentu memiliki jarak TDH yang besar karena dibatasi oleh spesifikasi pompa tertentu pada Tabel 3.

\subsection{Korelasi Daya Output Motor ESP terhadap Kedalaman Sumur (Depth)}

Berdasarkan Tabel 5, data kedalaman real pada tiap sumur berbeda-beda. Kedalaman ditinjau dari sekitar $1100 \mathrm{ft}$ hingga $3600 \mathrm{ft}$. Masing-masing kedalaman mewakili kapasitas motor yang berbeda-beda pula. Pada sumur A, kedalaman yang dimilikinya adalah $1141 \mathrm{ft}$ (347.8 m). Untuk menentukan kedalaman idealnya dapat digunakan Persamaan 7.

$$
\begin{aligned}
& \text { Depth ideal }=S F L+T D H \text { ideal } \\
& \text { Depth } \text { ideal }=516+788.87 \\
& \text { Depth } \text { ideal }=1304.87 \mathrm{ft}
\end{aligned}
$$

Perhitungan dilakukan terhadap semua sumur. Kemudian data hasil pengolahan yang berupa data real dan data hasil perhitungannya dimasukkan pada Tabel 7.

Tabel 7. Hasil Pengolahan Data Kedalaman Sumur

\begin{tabular}{|c|c|c|c|c|}
\hline No & $\begin{array}{c}\text { Nama } \\
\text { Sumur }\end{array}$ & $\begin{array}{c}\text { Daya Output Motor } \\
(\mathbf{K W})\end{array}$ & $\begin{array}{c}\text { Depth ideal } \\
(\mathbf{f t})\end{array}$ \\
\hline 1 & Sumur A & 22.37 & 1141 & 1304.87 \\
\hline 2 & Sumur B & 28.34 & 1134 & 1357.81 \\
\hline 3 & Sumur C & 28.34 & 1114 & 1330.64 \\
\hline 4 & Sumur BK180 & 46.98 & 3638 & 4412.28 \\
\hline 5 & Sumur BO235 & 70.84 & 2219 & 2826.65 \\
\hline
\end{tabular}

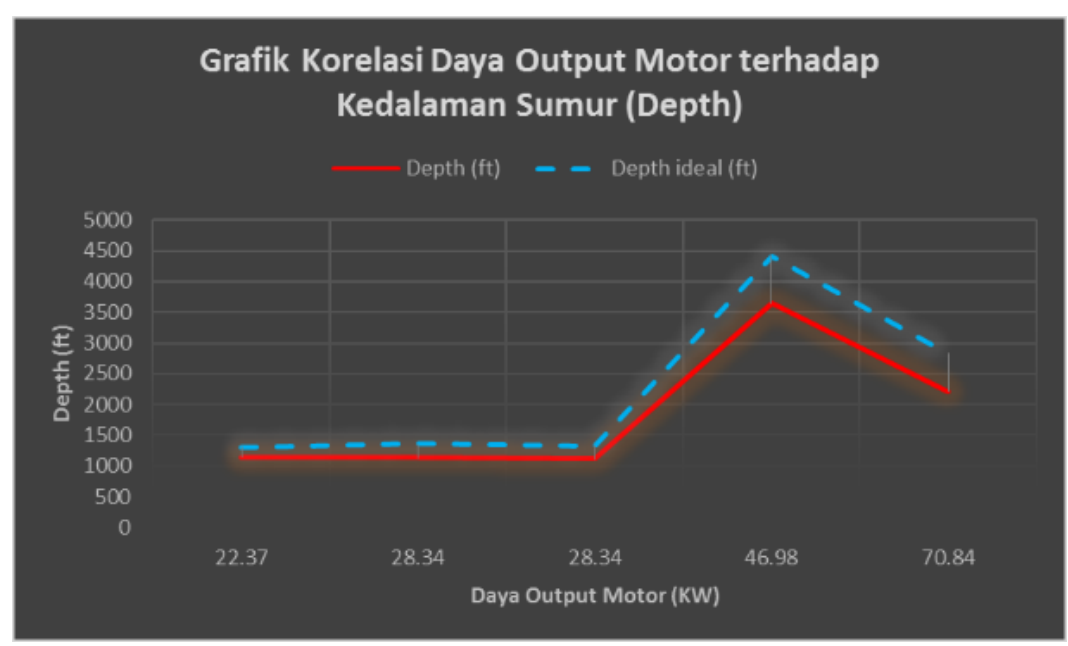

Gambar 12. Grafik Korelasi Daya Output Motor terhadap Depth

Gambar 12 menerangkan kedalaman real di beberapa sumur mendekati kedalaman idealnya. Pada sumur A,B, dan C memiliki kedalaman sekitar $1100 \mathrm{ft}$ sedangkan idealnya memiliki kedalaman $1300 \mathrm{ft}$. Meskipun selisih kedalamannya sekitar $200 \mathrm{ft}$, daya ouput 
pompa motor yang digunakan pada sumur A, B, dan C sudah mendekati kinerja optimalnya. Berbeda halnya dengan Sumur BK180 dan BO235. Dengan memiliki daya output yang lebih besar dibandingkan Sumur A,B, dan C, kedalaman yang dapat dicapai masih bisa lebih dalam lagi hingga mencapai kedalaman idealnya.

\subsection{Korelasi Daya Output Motor ESP terhadap Hasil Produksi Perjam (BFPH)}

Berdasarkan hasil data real pada Tabel 5, Sumur A memproduksi 1481,47 bpd atau setara dengan 61,73 bph, sedangkan pada Sumur B dapat memproduksi sebesar 1703,23 bpd atau setara dengan 70,97 bph. Berdasarkan perhitungan menggunakan Persamaan 10 dan 13, hasil produksi perjam maka diperoleh nilai perhitungan hasil produksi perjam (BFPHi) dimasukkan pada Tabel 8.

Tabel 8. Hasil Pengolahan Data Hasil Produksi Perjam

\begin{tabular}{|c|c|c|c|c|}
\hline No & Nama Sumur & Daya Output Motor (KW) & BFPH (Bph) & BFPHi (Bph) \\
\hline 1 & Sumur A & 22.37 & 61.73 & 160.49 \\
\hline 2 & Sumur B & 28.34 & 70.97 & 188.71 \\
\hline 3 & Sumur C & 28.34 & 64.87 & 194.95 \\
\hline 4 & Sumur BK180 & 46.98 & 53.18 & 90.43 \\
\hline 5 & Sumur BO235 & 70.84 & 189.35 & 171.00 \\
\hline
\end{tabular}

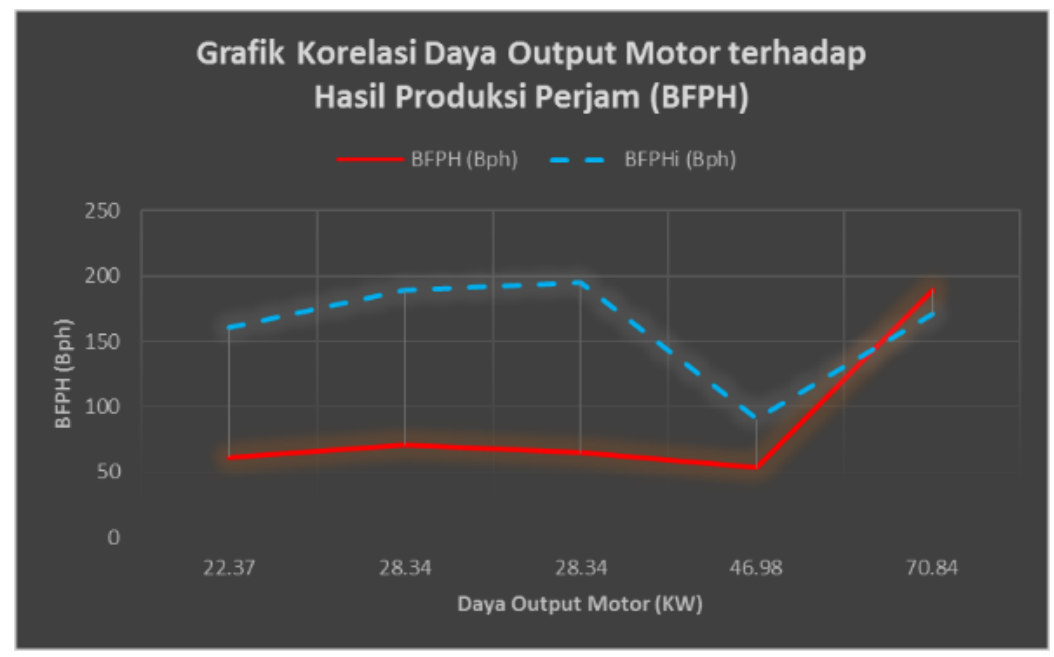

\section{Gambar 13. Grafik Korelasi Daya Output Motor terhadap BFPH}

Dari Tabel 8 dan Gambar 13 dapat dilihat bahwa, Sumur A, B, dan C memiliki hasil produksi yang masih jauh dari hasil produksi idealnya. Dengan kapasitas daya output $20 \mathrm{KW}-30 \mathrm{KW}$ dan spesifikasi pompa (Tabel 3), hasil produksi yang seharusnya dapat mencapai lebih dari 150bph. Pada Sumur BK180 dengan kapasitas daya output motor 47 KW, memiliki hasil produksi yang mendekati nilai produksi idealnya yaitu dengan selisih sekitar 30 bph tetapi hasil produksi yang diperoleh sangatlah kecil untuk kapasitas daya output motor yang sebesar $47 \mathrm{KW}$ yaitu 53,18 bph data rea/ dan 90,43 bph data ideal. Berbeda halnya dengan Sumur BO235, dengan menggunakan kapasitas daya output yang lebih besar, dengan kedalaman yang lebih kecil dari Sumur BK180 dan spesifikasi kapasitas pompa yang lebih kecil (Tabel 3), memiliki hasil produksi yang lebih besar dibandingkan hasil produksi idealnya. Hal ini membuktikan bahwa semakin besarnya kapasitas daya output motor, semakin besar pula hasil produksinya. 


\subsection{Korelasi Daya Output Motor ESP terhadap Hasil Produksi Perhari per- TDH(BFPD/TDH)}

Hasil produksi per-TDH merupakan parameter sumur yang terakhir dalam mencari korelasi daya output motor. BFPD/TDH juga dapat disebut sebagai debit maksimum tiap jarak pengangkutannya. Pada Tabel 5, nilai real untuk BFPD/TDH untuk semua Sumur berada pada sekitar $2.5 \mathrm{bpd} / \mathrm{ft}$, kecuali pada Sumur BK180 yang hanya bernilai $0.59 \mathrm{bpd} / \mathrm{ft}$. Untuk membandingkan nilai tersebut, diperlukan perhitungan nilai idealnya menggunakan Persamaan 14. Perhitungan nilai ideal BFPD/TDH dilakukan untuk semua sumur sehingga diperoleh nilai ideal BFPD/TDH-nya dan dimasukkan ke dalam Tabel 9.

Tabel 9. Hasil Pengolahan Data BFPD/TDH Ideal

\begin{tabular}{|c|c|c|c|c|}
\hline No & Nama Sumur & $\begin{array}{c}\text { Daya Output } \\
\text { Motor (KW) }\end{array}$ & $\begin{array}{c}\text { BFPD/TDH } \\
\text { (Bpd/ft) }\end{array}$ & $\begin{array}{c}\text { BFPDi/TDHi } \\
\text { (Bpd/ft) }\end{array}$ \\
\hline 1 & Sumur A & 22.37 & 2.37 & 4.88 \\
\hline 2 & Sumur B & 28.34 & 2.72 & 5.33 \\
\hline 3 & Sumur C & 28.34 & 2.57 & 5.69 \\
\hline 4 & Sumur BK180 & 46.98 & 0.59 & 0.74 \\
\hline 5 & Sumur BO235 & 70.84 & 2.62 & 1.75 \\
\hline
\end{tabular}

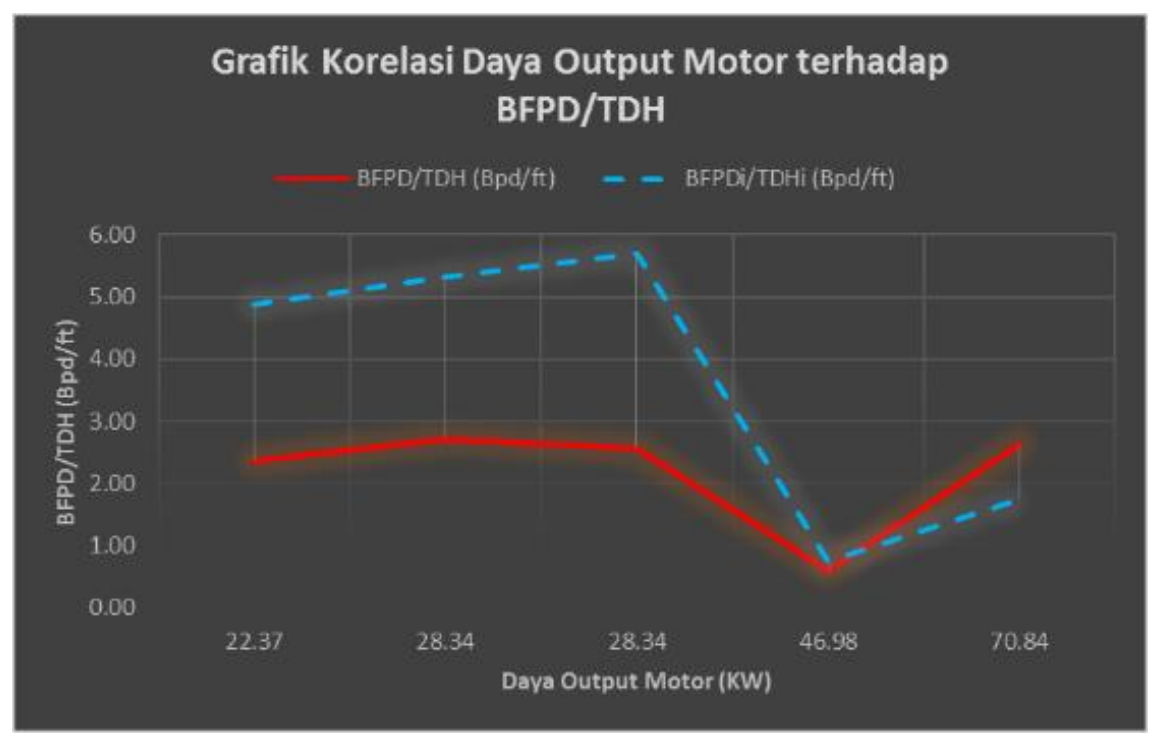

\section{Gambar 14. Grafik Korelasi Daya Output Motor terhadap BFPD/TDH}

Berdasarkan Tabel 9 dan Gambar 14, dapat dilihat bahwa nilai real dari BFPD/TDH pada Sumur A, B, dan C memiliki jarak yang jauh menuju nilai idealnya. Sumur B dan C juga memiliki perbedaan meskipun menggunakan motor yang memiliki daya output yang sama. Untuk Sumur BK180, nilai BFPD/TDH-nya sudah sangat mendekati nilai idealnya. Hal ini menunjukkan bahwa penggunaan motor dengan kapasitas daya output sebesar $46.98 \mathrm{KW}$ dapat dioptimalkan untuk memproduksi fluida yang ada di dalam sumur dengan kedalaman yang sebesar $3638 \mathrm{ft}$.

Berbeda halnya dengan Sumur BO235, nilai rea/BFPD/TDH-nya mampu melewati batas nilai idealnya. Hal ini membuktikan bahwa, pemanfaatan kapasitas daya output motor yang besar dapat menghasilkan produksi perjarak angkutnya semaksimal mungkin. Dengan daya output sebesar $70.84 \mathrm{KW}$ mampu menghasilkan BFPD/TDH sebesar $2.62 \mathrm{bpd} / \mathrm{ft}$ yang lebih besar dibandingkan nilai idealnya yang hanya $1.75 \mathrm{bpd} / \mathrm{ft}$. 


\subsection{Korelasi Kapasitas Daya Motor terhadap Friction Loss}

Di dalam kasus ini, kedalaman untuk masing-masing sumur bernilai lebih dari $1000 \mathrm{ft}$. Untuk itu, diperlukan perhitungan data feet friction loss per1000 feet (hf) untuk menentukan besarnya pengaruh hilangnya energi akibat gesekan fluida di dalam pipa terhadap penggunaan kapasitas daya motornya. Sesuai dengan Persamaan 16, maka diperoleh data friction loss pada Tabel 10.

Tabel 10. Tabel Pegolahan Data Friction Loss

\begin{tabular}{|r|r|r|r|l|}
\hline No & Po (KW) & BFPD (Bpd) & hf (ft) & Keterangan \\
\hline 1 & 22.37 & 1407.6 & 3.86 & Sumur A \\
\hline 2 & 22.37 & 1524.4 & 4.47 & Sumur A \\
\hline 3 & 22.37 & 1512.4 & 4.41 & Sumur A \\
\hline 4 & 28.34 & 1722.5 & 5.60 & Sumur B \\
\hline 5 & 28.34 & 1687.1 & 5.39 & Sumur B \\
\hline 6 & 28.34 & 1700.1 & 5.47 & Sumur B \\
\hline 7 & 28.34 & 1310.7 & 3.38 & Sumur C \\
\hline 8 & 28.34 & 1687.9 & 5.40 & Sumur C \\
\hline 9 & 28.35 & 1672.4 & 5.31 & Sumur C \\
\hline 10 & 70.84 & 4548 & 33.77 & Sumur BO235 \\
\hline 11 & 70.84 & 4537 & 33.62 & Sumur BO235 \\
\hline 12 & 70.84 & 4548 & 33.77 Sumur BO235 \\
\hline 13 & 46.98 & 1303 & 3.34 & Sumur BK180 \\
\hline 14 & 46.98 & 1309 & 3.37 Sumur BK180 \\
\hline 15 & 46.98 & 1217 & 2.95 & Sumur BK180 \\
\hline
\end{tabular}

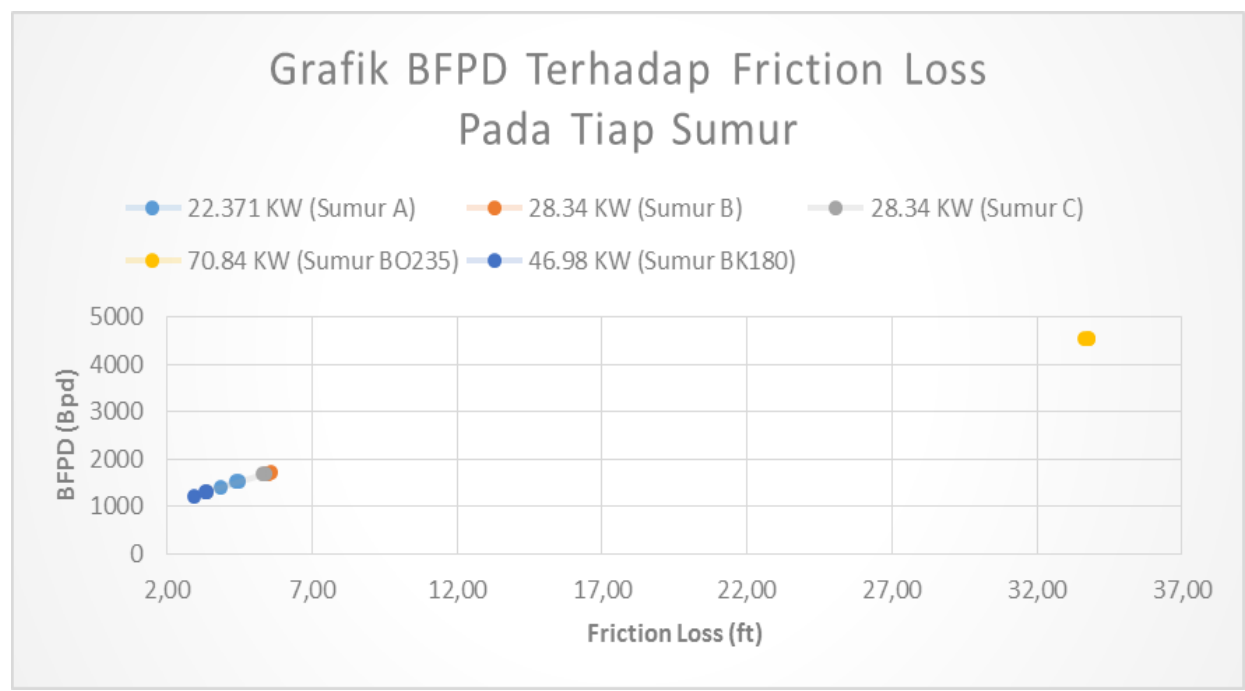

Gambar 15. Grafik BFPD terhadap Friction Loss Pada tiap Sumur 


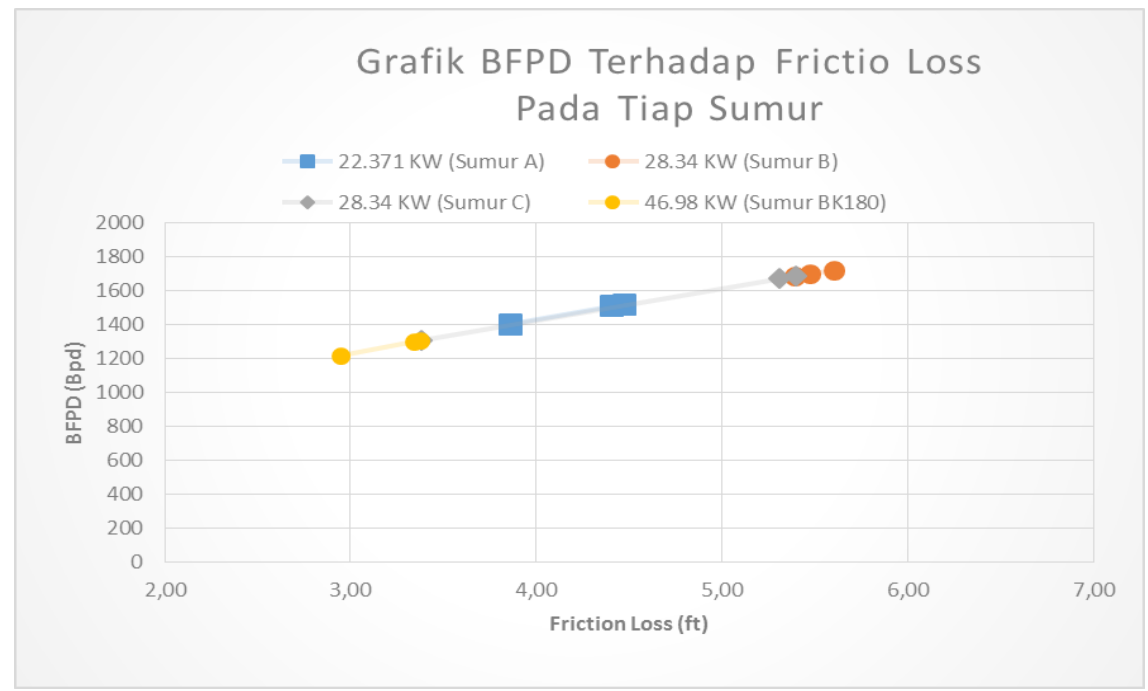

Gambar 16. Grafik BFPD terhadap Friction Loss Pada tiap Sumur dengan Skala 2-7

Dari Gambar 15 dan Gambar 16, garis berwarna merah merupakan nilai friction loss yang diperoleh sumur A. Garis biru merupakan nilai frcition loss pada sumur B. Garis hijau putusputus merupakan nilai friction loss pada sumur C. Garis hijau tebal (Gambar 15) merupakan nilai friction loss pada sumur BO235 dan Garis Kuning merupakan nilai friction loss pada sumur BK180. Dari grafik tersebut dapat dilihat bawha sumur yang memiliki kedalaman paling dalam yaitu BK180 sebesar lebih dari $3600 \mathrm{ft}$ dengan hasil produksi perhari sekitar $1300 \mathrm{bpd}$ mengalami friction loss yang paling kecil yaitu bernilai 2,95 - 3,37 ft. Sedangkan sumur A, B, dan C, yang memiliki kedalaman yang sekitar $1100 \mathrm{ft}$ dengan hasil produksi perhari sekitar 1500bpd memiliki friction loss yang hampir sama yaitu berkisar 3,38 - 5,60. Tetapi, untuk sumur BO235 yang memiliki kedalaman sumur sekitar $2200 \mathrm{ft}$ dengan hasil produksi perhari lebih dari $4500 \mathrm{bpd}$, mengalami friction loss yang paling besar yaitu sekitar $33,6 \mathrm{ft}$.

Dari hasil yang diperoleh berdasarkan Tabel 10, Gambar 15, dan Gambar 16 dapat dianalisis bahwa kedalaman yang besar tidak mempengaruhi friction loss yang terjadi. Tetapi, hal ini diakibatkan oleh kapasitas daya motor yang besar mempengaruhi besarnya laju fluida di dalam pipa yang menimbulkan gesekan yang semakin besar anatara fluida terhadap dinding dalam pipa sehingga terjadi hilangnya energi yang ditimbulkan oleh gesekan tersebut.

\section{KESIMPULAN}

Berdasarkan Hasil Pengolahan Data dan Analisis Sistem dapat disimpulkan bahwa:

a. Kapasitas daya output motor dapat mempengaruhi besarnya nilai Total Dynamic Head (TDH) pada suatu sumur minyak. Sumur A, B, dan C memiliki nilai TDH sekitar $600 \mathrm{ft}$ dan dapat diperbesar hingga sekitar $800 \mathrm{ft}$. Sumur BK180 memiliki nilai TDH sebesar $2166 \mathrm{ft}$ dan dapat diperbesar hingga 2940,28 ft. Sumur BO235 memiliki besar TDH $1737 \mathrm{ft}$ dan dapat diperbesar hingga 2344,65 ft.

b. Kapasitas daya output motor dapat memperbesar jarak kedalaman pemasangan sistem ESP pada suatu sumur minyak. Pada Sumur A, B, dan C, memiliki kedalaman sumur sekitar $1100 \mathrm{ft}$ dan dapat diperbesar hingga jarak kedalaman sumur sekitar $1300 \mathrm{ft}$. Pada Sumur BK180, memiliki kedalaman sumur minyak sebesar $3638 \mathrm{ft}$ dan dapat diperbesar 
hingga kedalaman 4412,28 ft. Sumur BO235 memiliki kedalaman sumur sebesar $2219 \mathrm{ft}$ dan dapat diperbesar hingga kedalaman 2826,65 ft.

c. Kapasitas daya output motor dapat meningkatkan hasil produksi pada suatu sumur minyak. Pada Sumur A, B, dan C, memiliki hasil produksi sekitar 65 bph dan dapat ditingkatkan menjadi sekitar $180 \mathrm{bph}$. Pada Sumur BK180 memiliki nilai hasil produksi sebesar 53,18 bph dan dapat ditingkatkan hanya sampai 90,43 bph. Untuk Sumur BO235 memiliki hasil produksi sebesar 189,35 bph yang melebihi dari nilai idealnya yang hanya sebesar 171 bph.

d. Kapasitas daya output motor dapat meningkatkan hasil produksi tiap jarak TDH-nya pada sistem ESP. Pada Sumur A, B, dan C besarnya BFPD/TDH yang bernilai sekitar 2,5 bpd/ft dapat ditingkatkan 2 kali lipatnya menjadi sekitar 5,0 bpd/ft. Pada Sumur BK180 yang memiliki nilai BFPD/TDH sebesar $0,59 \mathrm{bpd} / \mathrm{ft}$ dapat ditingkatkan menjadi $0.74 \mathrm{bpd} / \mathrm{ft}$. Pada Sumur BO235 nilai TDH yang diperoleh $2.62 \mathrm{bpd} / \mathrm{ft}$ melebihi nilai idealnya yang bernilai $1.75 \mathrm{bpd} / \mathrm{ft}$.

e. Kapasitas daya motor dapat mengakibatkan terjadinya friction loss pada tubing pompa. Pada Sumur A, B, dan C $(22,37 \mathrm{KW}, 28,34 \mathrm{KW}$, dan 28,34 KW), terjadi friction loss maksimum hingga 5,60 ft. Sumur BK180 $(46,98 \mathrm{KW})$ terjadi friction loss maksimum higga 3,37 ft. Sedangkan Sumur BO235 (70,84 KW) terjadi friction loss maksimum hingga 33,77 ft. Semakin besar kapasitas daya motor yang digunakan semakin besar pula friction loss yang dialami oleh pumping system pada sumur minyak.

\section{UCAPAN TERIMA KASIH}

Pada ucapan terimakasih ini, penulis berterimakasih kepada PT Baker Hughes Indonesia yang telah memberikan kesempatan untuk melakukan studi kasus yang berkaitan dengan penelitian ini, baik dari segi waktu, tempat, serta data yang diperoleh untuk melakukan penelitian ini.

\section{DAFTAR RUJUKAN}

Centrilift. (2006). GCS Vortex Motor Controller operator's Manual. USA: Baker Hughes Indonesia.

Hughes, Baker. (2006). Electrical Submersible Pump Motor Controller Operator's Manual. Baker Hughes Indonesia.

Hughes, Baker. (2009). Submersible Pump Handbook Ninth Edition. USA: Baker Hughes Indonesia.

Pungky Hermawan, Pungky. (2002). Perbandingan Hasil Pengujian Horisontal dan Vertikal pada Pompa Roda Electric Submersible Tipe DN 3000. Depok: Teknik Mesin UI.

Robi Irsamukhti, Robi. (2012). System and Technology of Geothermal. Garut: PLTP Kamojang.

Wiharya, Chandra; Suyono, Hadi; dan Hasanah, Rini Nur. (2014). Analisis Voltage Sag pada Sistem Tenaga Listrik PT. Petrochina International Ltd. Sorong. Jurnal EECCIS Vol. 1, No. 1. 